\title{
Do pressuposto dialógico na pesquisa: o lugar da multiplicidade na formação (docente) em rede
}

\author{
The dialogue presuposition in the search: \\ the place of multiplicity in training (teacher) network
}

\begin{abstract}
Resumo: O presente artigo trata de problematizar a relação entre tecnologia e escola através de dois projetos de investigação: o PROVIA e o CIVITAS. A formação decorrente de tais projetos incide sobre o ensino superior e a comunidade nas escolas e possui dimensões epistemológicas e metodológicas que apontam para a vivência do conhecimento em redes presenciais e à distância. A análise deste contexto é apreendida, fundamentalmente, através de Deleuze e Bakhtin que trazem subsídios orientando o entendimento da rede como dialógica e polifônica, afirmação da diferença e nascimento da autoria no seio da complexidade relacional. A idéia, portanto, é expressar que o encontro da Escola com a tecnologia localizada dentro de campo de análise entendido como acontecimento estando envolto de imprevisibilidade, multiplicidade e proliferação de sentidos para o conhecimento e, conseqüentemente, para a vida.
\end{abstract}

Palavras-chave: Pesquisa. Dialogia. Formação docente.

Abstract: This article comes to question the relationship between technology and school through two research projects: PROVIA and CIVITAS. The formation resulting from such projects fall upon on higher education and community schools and has epistemological and methodological dimensions that point to the experience of knowledge networks in presencial and distance. The analysis of this context is perceived by mainly Deleuze and Bakhtin directing the subsidies about the network as dialogic and polyphony, assertion of difference and birth of authorship in the relationa complexity. The idea is to express the meeting of the Schoo with the technology is located within the field of analysis perceived as being event including unpredictability, proliferation and multiplicity of meanings for the knowledge and, consequently, for life.

Keywords: Search. Dialogue. Higher Education.

AXT, Margarete. Do pressuposto dialógico na pesquisa: o lugar da multiplicidade na formação (docente) em rede. Informática na Educação: teoria \& prática, Porto Alegre, v. 11, n. 1, p. 91-104, jan./jun. 2008.

\author{
Margarete Axt \\ Universidade Federal do Rio Grande do Sul, Porto Alegre, Brasil
}

\section{Prática pedagógica como foco da pesquisa}

A formação docente, como eixo temático e problemático, tem se constituído, desde longa data, em dispositivo para pensar questões de caráter conceitual-metodológico e epistemológico, produzindo conhecimento e atualizando modos de convivência e in(ter) venção em rede, no âmbito da pesquisa em educação. Quando se fala no conceito de rede, pensa-se antes nas redes relacionais de convivência, que podem ser tanto a distância, quanto presenciais. E quando se pensa a in(ter) venção, pensa-se nela como aquele ato que não se reproduz, sendo único e irreversível, emergindo exatamente num certo espaçotempo, o contexto para o qual foi inventado...

como um conceito que evidencia no fenômeno clínico, pedagógico, político, artístico... a sua função criadora, inventiva e trágica. A in(ter)venção é criadora e inventiva porque estamos operando em nossas práticas a partir de um novo eixo de pensamento filosófico, científico e artístico: não basta refletir sobre, é necessário criar um movimento. Intervir é inventar, é morrer e é nascer. A in(ter)venção é trágica, porque o destino da in(ter)venção é a sua própria morte (AXT; KREUTZ, 2003: 330).

Essa linha de pesquisa e formação tem possibilitado ao nosso grupo ${ }^{1}$ articular-se em 
torno de dois projetos de investigação, voltados, respectivamente, às redes relacionais de convivência a distância e às redes relacionais de convivência presenciais: tanto a formação no ensino superior, quanto a formação continuada em serviço têm ajustado seu foco nas práticas docentes em sala de aula, enquanto atravessadas pelos efeitos do encontro/confronto entre tecnologias e escola. Os trabaIhos decorrentes inscrevem-se no plano das aprendizagens, das relações éticas, da expressão estética, da produção de sentido e de autoria, problematizando processos de investigação do virtual, da criação e da invenção, implicando saberes instituídos em campos específicos, bem como a produção de modos de subjetivação então emergentes ${ }^{2}$. Contudo, para falar do formato que as experimentações em rede vêm assumindo em nossos estudos, parece relevante considerar alguns pontos que vêm transversalizando e até empanando com aspectos redutores este diálogo entre a pesquisa em Educação e os contextos empíricos de sala de aula.

\section{Alguns redutores}

O fato de ter-se instalada uma nova ordem econômica internacional, globalizada e na qual estamos todos imersos, contribuiu, entre outras coisas, e para além da difusão das tecnologias da informação e comunicação e de sua conexão em rede mundial, para uma proposta concreta de considerar a Educação como bem de consumo, como produto, na forma de pacotes, declarando-a sujeita às regras do comércio internacional, no marco de uma economia de mercado propalada pela Organização Mundial do Comércio (OMC). I sto é particularmente válido para a Educação a distância (EAD) no ensino superior. Contudo, tal perspectiva tem, também em muitos momentos, entrado subrepticiamente na escola, transfigurada em políticas públicas: percebe-se isso na medida em que estas políticas acabam por acentuar a idéia de pacotes curriculares homogêneos, apontando como bom desempenho escolar o consumo também homogêneo desses conteúdos, o que seria mensurado através de ava- liações, novamente homogeneizantes, que estariam matematizando e comparando nacionalmente as competências (quais competências?!?) dos alunos e, por extensão, também as dos professores. Professores que acabam por ficar constrangidos frente a um "mau desempenho" de seus alunos.

Outro efeito da globalização que parece por vezes atingir a escola é o de precipitação dos acontecimentos. Um rápido sobrevôo sobre o contexto contemporâneo logo nos mostra os efeitos de simultaneidade que os meios globalizados de comunicação (e também dos transportes) podem produzir, trazendo como contrapartida a aguda tomada de consciência quanto à incapacidade de manter sob controle e sob determinada ordenação o curso da história. O efeito é de aceleração e de precipitação, não apenas da história e de seus processos de transformação, mas do próprio cotidiano, trazendo uma sensação avassaladora de vertigem: parece que somos o tempo todo devedores da notícia ou da informação mais recente; que o nosso cotidiano se apresenta conservador, rotineiro, estagnante, prendendo-nos em suas malhas, dificultando-nos avançar; que estamos sempre desatualizados em relação à produção cultural-científica e aos desenvolvimentos da tecnociência ${ }^{3}$.

Paralelamente (e de uma maneira que pode parecer paradoxal), o mundo parece que resolve este problema de excesso acontecimental pela via de um excesso simbólico-informacional, porém de um modo que nos aparece extremamente ordenado, padronizado: fatos fabricados segundo uma só lente em perspectiva; uma dada imagem e uma dada informação produzindo o fato; e o fato se tornando a versão oficial do acontecimento, amputando-o em sua multiplicidade espaço-temporal, em sua própria possibilidade de problematização. Basta conectar-se aos meios de comunicação de massa para perceber que, hora após hora, e em todas as emissoras de rádio e TV, as notícias são as mesmas, as mesmas formulações, os mesmos pontos de vista, até o mesmo encadeamento; fatos vão sendo simplesmente apresentados e conectados uns aos outros numa enfadonha seqüência por justaposição,

\footnotetext{
2 São alguns exemplos dessa produção, para além de teses e dissertações, artigos como: Axt; Martins ( 2008); Mutti; Axt (2008); Axt (2007); Alves; Thomaz; Nunes; Axt (2007); Axt (2006), Maraschin; Axt (2005); Axt (2205; 2004); Axt; Elias (2003); Axt; Kreutz (2003); Axt et al (2003). Parte da produção do grupo está disponível em http://www. lelic.ufrgs.br , publicações LELIC.

${ }^{3}$ Marc Augé, em 1994, já comenta sobre este excesso simbólico que atravessa o cotidiano.
} 
crescentemente planificados, homogeneizados, levando, pelo excesso, a uma espécie de letargia, enquanto afetação.

A Educação, vale dizer também, a Escola, como componente deste conjunto sócio-econômico-cultural, e como parte deste estado de coisas, refrata-o, e reflete a seu modo o que refrata. Assim, muitas vezes a Escola parece que repete este modelo redutor, ao querer dar conta de uma superabundância de conteúdos oriundos do campo científico, organizando na forma de um currículo muito ordenado e cronologizado e de caráter fechado, todo este excesso informacional-conteudístico.

Por outro lado, não deixa de ser estratégico num modelo redutor, que um tal currículo seja homogeneizado, e complementado também, por um conjunto de práticas docentes discursivas verbalistas, não-problematizadoras, na ótica do pensamento único e convergente, apresentando como uma característica relevante a falta de afetação, ou de implicação por parte de professores. Neste contexto, estudantes também não implicados, é muito provável que se coloquem frente ao professor (e à possibilidade de conhecimento) como espectadores, na expectativa do espetáculo, o que nem sempre se cumpre, para decepção dos mesmos. Há, por vezes, um implícito de que a aprendizagem dos conteúdos informacionais dependeria de uma organização prévia do professor e do currículo, aliada a uma perfomance do mestre frente às câmeras, tipificadas nos olhos dos estudantes. Os efeitos, de parte a parte, podem ser os de uma produção apenas discursiva, prolífera e nada criativa, marcada pelo senso-comum e pela banalização dos conceitos. Reciprocamente, os conceitos, minados em sua consistência, perdem potência como dispositivos para produzir aprendizagem, dissociando teoria e prática, num processo crescente de esvaziamento de sentido.

\section{A relação professor-aluno}

Ao mesmo tempo, porém, em que esses aspectos vêm reduzindo o diálogo entre a pesquisa em Educação (a distância) e os contextos empíricos de sala de aula (virtual), e na contramão de todo este estado de coisas, ciência e filosofia começam a ser bem sucedidas em suas propostas de visibilidade, discutindo intensamente as tendências da complexidade pós-estruturalista (PRIGOGINE; STENGERS, 1997), da fragmentação da matriz identitária (HALL, 1998; FIGUEIREDO, 1989), e da contínua produção da diferença (DELEUZE, 1988). Sob todos os ângulos e em todos os níveis, aprende-se a ver, com Latour (1994), Deleuze e Guattari (1997a;b;c), e outros, a emergência dos coletivos híbridos capturados em agenciamentos maquínicos e de enunciação, de diversas ordens, e com efeitos na produção das subjetividades contemporâneas.

A noção de agenciamento (material ou maquínico), dirão o filósofo Gilles Deleuze e o psicanalista Félix Guattari (1997c, p. 31-32), remete-nos a um "estado preciso de mistura de corpos, ou amálgama, em uma sociedade, compreendendo atrações e repulsões, simpatias e antipatias, as alterações, as alianças, as expansões que afetam todos os corpos envolvidos no agenciamento, uns em relação aos outros". E as ferramentas, o avanço tecnológico "não são separáveis das simbioses ou amálgamas que definem um agenciamento maquínico natureza-sociedade". Como defendem, "uma sociedade se define por seus amálgamas e não por suas ferramentas". No seu aspecto coletivo ou semiótico, o agenciamento (de enunciação) remete a "uma máquina de expressão", dizem os autores, "cujas variáveis determinam o uso dos elementos da língua". Esses não valem por si, mas pelos agenciamentos coletivos de enunciação que os juntam e pelos modos como os juntam e combinam. Combinações/amálgamas múltiplos se fazem simultaneamente a velocidades diferentes, criando fluxos.

Esta espécie de contracorrente do pensamento e da cultura tem continuamente produzido condições de possibilidade para novas tomadas de decisão, busca de outros rumos, revisões em inúmeros setores da sociedade, incluindo-se nesse movimento a Educação e a Pesquisa em Educação.

No que tange a esta última, alguns dos achados do LELIC ${ }^{4}$, nas perspectivas da linguagem, da complexidade e da diferença têm

\footnotetext{
${ }^{4}$ Estudos que focalizam esta dramática estão sendo desenvolvidos, segundo temáticas e níveis de aprofundamentos diferentes, por pesquisadores do LELIC, em trabalhos TCC (graduação Pedagogia/UFRGS, Carla Inês Freitas), de dissertação (Paloma Dias Silveira e Luciana Lunkes) e de tese (Márcio Marinho Martins, José Ricardo Kreutz e Gislei Domingas Lazzarotto (Programa de Pós-Graduação em Educação - PPGEDU/UFRGS).
} 
nos mostrado que, se de um lado, o discurso engajado, crítico-político, oriundo dessas tendências contemporâneas do pensamento filosófico, pode constituir condições propícias para uma tomada de posição politizada do professor em formação, em nível pessoal; por outro lado, não parece tão evidente a sua influência (do discurso) sobre a qualidade da prática docente, de modo que possa colocá-la a salvo dos processos de redução, alguns já referidos. Neste caso, discurso e prática não se afetam de maneira direta nem automática, são de natureza diversa e pertencem a âmbitos diferentes, parecendo não se recobrir mutuamente. Se se entender a prática docente como consistindo essencialmente na relação que se estabelece entre professor e aluno, um entre-sujeitos, esta prática, ao que se evidencia, permanece transparente, invisível para o professor no seu cotidiano escolar (e também para o formador).

Numa ponta da relação tem-se um professor, cioso de sua missão, de seus objetivos, do conteúdo curricular a ser preparado na forma de lições quotidianas; e na outra ponta, tem-se um aluno que olha para o professor (e o seu conteúdo) e precisa decidir ${ }^{5}$, mediante uma tomada de posição subjetiva, mediante uma escolha, se quer, ou não, aprender: precisa decidir se há, ou não, desejo de aprender e de conhecer... Já a relação em si mesma, entre este professor e este aluno, não tem densidade, não tem opacidade, vêmo-la como transparente, completamente naturalizada! Contudo, também entendemos que seja exatamente esta relação que irá, no âmbito da sala de aula, constituir o "nó górdio"6 da aprendizagem.

Entendemos que, na formação, o foco somente no discurso não torna visível esta relação (nem para o professor, nem para o formador), de modo a que o pensamento reflexivo se possa deter nela.

Para que este campo relacional possa ser visibilizado em todas as suas tensões (e eventualmente em seus movimentos de transformação), supõe-se que haja necessidade de incidência de luz, criando um foco de atenção luminoso que refrate e reflita a relação para outro plano, o plano das tomadas de posições; mas para que este campo possa ser iluminado, ele precisará estar suficientemente opaco de tal modo que possa enredar a luz em seu meio, refratá-la e refleti-la, refletindo com ela a própria relação; opacificar o campo relacional seria então adensá-lo. E adensar este campo implicaria situar no interior do campo (como um transbordamento do seu fora para o seu dentro), também aqueles condicionantes que o podem reduzir a modos estratificados de ação e relação.

Como adensar suficientemente um campo relacional, de tal modo que, ao ser iluminado pela atenção, a relação que o habita possa ser refratada e refletida para o plano do pensamento e das tomadas de posição, tornando visíveis e, ao mesmo tempo, manipuláveis (no sentido dos processos de transformação) os modelos redutores que a prendem numa camisa de força, liberando-a para o exercício de outros modos éticos e estéticos de conviver na sala de aula? Eis nossa questão de fundo.

Compreendemos os conceitos de ética e estética no sentido de G. Deleuze (1996:79-80), o qual, em sintonia com o historiador e filósofo M. Foucault, nos fala da ética como um "conjunto de regras facultativas que fixam o valor do que fazemos, do que dizemos, segundo o modo de existência que isso implica. Modos de existência ou estilos de vida estão sempre implicados nos gestos, na palavra, e são eles que nos constituem como este ou aquele". A diferença entre a ética e a moral está, segundo os autores, em que a moral se apresenta "como um conjunto de regras que coagem, regras de um tipo especial que consistem em julgar as ações e as intenções a partir de valores transcendentes (está bem, está mal...)".

Ainda inspirado em Foucault, Deleuze (1996) nos fala de uma estética que remete sempre a um estilo, um estilo de vida: não algo na instância da pessoa que seja pessoal, mas na instância da invenção de uma possibilidade de vida, de um modo de existência, seja no interior de uma obra, seja no interior mesmo da existência à qual tende, segundo aquilo que detém em liberdade, em criatividade (variável, em consonância com os contextos), sem recorrer a valores transcendentes.

\footnotetext{
${ }^{5}$ Usam-se os termos "decidir" e "escolha", como força de expressão para uma manifestação de adesão (em relação de tensão com sentidos de resistência), que vem a ser da ordem do inconsciente.

${ }^{6}$ Um problema complexo, em referência a uma história, que remonta ao século VIII a.C. na Frígia, segundo a qual um rei de nome Górdio amarrou a sua carroça de bois com um nó a uma coluna, no templo de Zeus, nó este impossível de desatar.
} 


\section{0 pressuposto dialógico como operador das experimentações}

Essa questão nos leva a querer desenhar um modo de inserção da pesquisa no campo educacional que, ao mesmo tempo em que reconhece a influência dos modelos redutores na determinação das práticas docentes, quer ultrapassar a idéia de justificativa, para avançar em direção à própria intencionalidade da pesquisa, constituindo-se em operador de uma proposta metodológica de formação: ter-se-á, assim, simultaneamente, na mesma interface, pesquisa e formação (formação, seja no plano do ensino, seja no da extensão). Nesta medida, compreendemos que cresce dramaticamente, em importância, a necessidade de considerar-se, no fazer investigativo, as dimensões éticas e estéticas postas nas relações de convivência, entre pesquisador e educadores em formação, relações estas que certamente deslizarão para o plano da sala de aula desses mesmos educadores, numa aposta do potencial de contágio que trazem em si: contágio, por aquilo, da relação, que reverbera em outras relações, fazendo-a durar.

Tem-se, então, um primeiro ponto a ser considerado, segundo a perspectiva que nos captura e encanta: há que se aprender a tratar, em ação, com a diversidade e a complexidade dos coletivos em Educação. Essa exigência, que entendemos esteja posta para todo o campo educacional, aponta para a relevância de situar a pesquisa e o locus de sua problematização nos próprios contextos de existência da ação educativa - e não mais segundo experimentos bem delimitados e assépticos, que trazem em si a precisão cirúrgica das construções em laboratório, cujos resultados seriam depois aplicados ao universo mais amplo da realidade empírica, numa operação simples de tradução literal da verdade sobre.

Esse viés de que as problematizações sejam tratadas nos próprios espaços de realidade de onde emergem, para aí crescerem, numa relação de coexistência e solidariedade, tanto com o campo empírico, como com o pensamento teórico-conceitual e interpretativo que Ihes dá sustentação, deriva principalmente:

a) de que é já impossível apenas um trabaIho de tradução literal7, pelo pesquisador, de resultados obtidos sob condições controladas (e assépticas), para os contextos de realidade concreta, contextos híbridos e abertos, em que tudo pode escapar, em que tudo pode passar a integrar o conjunto, na própria medida das alianças, das misturas...8

b) e de que esse trabalho de tradução literal, que antes parecia não oferecer maiores dificuldades, se tornou inviável para o pesquisador/educador, na medida em que: tanto Ihe foi sendo dado a ver a impossibilidade de uma mera transposição do empírico para o plano da linguagem e dos modos de pensamento; quanto, ao mesmo tempo, Ihe foi sendo imputado, por pressão dos próprios coletivos nos contextos de realidade, reconhecer, hoje, o efetivo estatuto de existência dessa diversidade, dessa multiplicidade, dessa complexidade.

Em outras palavras, e como nos lembra Bakhtin (1997), todo "fenômeno particular está imerso no caos dos princípios primários da existência". Então, embora se possa imputar autonomia de sentido aos fenômenos da realidade concreta, mediante operações de abstração cognitiva e de tradução (não literal) para o plano da linguagem, isolando-os, assim, dos atos empíricos concretos, na compreensão efetiva, real, todos os atos (e os fenômenos a eles ligados) se fundem indissoluvelmente num único e mesmo processo de compreensão implicada. Vale dizer que a compreensão é, então, neste viés teórico-conceitual e metodológico, efeito de uma pragmáti-

\footnotetext{
${ }^{7}$ Vemos uma diferença entre a pretensão de uma tradução literal que deseja dar conta da totalidade do que está sendo traduzido (como se fosse possível uma superposição completa entre linguagem e o que se presta a ser falado) e uma tradução que reconhece, no próprio movimento de traduzir, a contingência de não poder cobrir, pela tradução, a totalidade do que está sendo traduzido. Nesta acepção, Amorim (2001, p. 18), por exemplo, comenta que traduzir é sempre "[...] mostrar a descontinuidade, o intervalo [...]", sendo que os processos de interpretação, compreensão (e mesmo de explicação) não deixam de ser, a fortiori, um trabalho de tradução.

${ }^{8}$ Deleuze e Guattari (1997b, p. 18-37), tratam as alianças e misturas através do conceito de rizoma (retirado da biologia) e que diria do funcionamento central do desejo, ao qual estaria ligado, por suposto, todo o operar humano: "[...] é sempre por rizoma que o desejo se move e produz. $E$ se a árvore dá conta da filiação, e a série, da dependência, o rizoma é aliança, unicamente aliança, e tem como tecido a conjunção 'e... e... e...' O rizoma parte do meio, pelo meio [...] o meio é o lugar onde as coisas adquirem velocidade."
} 
ca: uma pragmática assim se constituindo pela mediação e atravessamentos dos contextos e dos sentidos aí produzidos, por implicação dos próprios atos empíricos concretos nestes contextos e suas interpretações possíveis.

Nesta perspectiva de uma pragmática, o recorte metodológico a ser efetuado num certo empírico da realidade concreta, para efeitos de pesquisa, viabiliza que se tracem planos $^{9}$, que sejam, ao mesmo tempo: de referência para o pensamento investigativo, de consistência para o pensamento conceitual, e de composição para arte; planos transversalizados pelo pensamento em rede, afirmando a um só tempo a dimensão ético-relacional e a dimensão estético-existencial. Planos híbridos, complexos, abertos aos fluxos do fora do próprio campo, sem que as linhas que o unem a este fora sejam totalmente cortadas.

Neste sentido é que erigir ou traçar um plano para a pesquisa é diferente da pesquisa em laboratório, é neste sentido que, respectivamente, a experimentação difere do experimento - o recorte operado a partir do traçado do plano não extrai o plano do seu contexto, não rompe com as linhas que o atravessam e que derivam de fora das suas fronteiras; também não rompe com as linhas que, ao atravessá-lo, novamente se perdem para além dessas fronteiras. Ao contrário, são as próprias fronteiras que constituem o meio, onde tudo adquire maior velocidade, produzindo acelerações e inflexões como efeito das relações de força entre fora e dentro do plano: inflexões em que o fora dobra-se para dentro ( "in-plicare", dobrar para dentro), forçando o dentro do plano, mas também dando-se a ver e a ser enunciado; e o dentro, enquanto efeito da dobra do próprio fora, para o fora transborda ("ex-plicare", dobrar para fora), constituindo, na transitoriedade das relações, modos particulares e efêmeros de iluminar o que ilumina, e modos particulares e provisórios de enunciar o que enuncia.

Em outras palavras, supõe-se que, no traçado dos planos em que erigirá a pesquisa, o pesquisador opere simultaneamente dois movimentos: o de implicar-se vivencialmente com o campo empírico, dobrando-se com o dentro, o movimento de implicação-vivenciação; e o de explicar (no sentido de uma tradução interpretativa, não literal) as relações sobre o plano ao dobrar-se com o fora, transbordando as fronteiras do dentro, distanciando-se, o movimento de distanciação-explicação. A linguagem bakhtiniana, nos remeteria aos conceitos de cronotopos e de exotopia: de um lado, o exercício cognitivo de afastar-se dos kronotopoi, enquanto contextos espaço-temporais da ação, da produção, nos quais se encontra imerso o pesquisador, com vistas à captura, mesmo que apenas parcial, de uma totalidade; de outro, a própria condição de exterioridade de um pesquisador em relação a uma obra, a uma cultura, a um campo empírico, a um tempo, e que, na busca de compreender estas produções exercita simultaneamente processos de adentramento nos contextos em pauta e novamente outros tantos afastamentos.

Um segundo ponto se mostrou relevante nesta busca de entendimento da pesquisa em Educação, enquanto, ao mesmo tempo, dispositivo para intervenção educativa, e reciprocamente, da intervenção educativa como dispositivo metodológico para pensar a pesquisa: a possibilidade de entendimento, oferecida por alguns autores, em especial Bakhtin (1997), de que a pesquisa em Ciências Sociais e Humanas tem como condição a Dialogia. Isso irá significar em Educação, que a pesquisa não se refere, em absoluto a uma forma monológica de conhecimento em que o intelecto contempla uma coisa e se pronuncia sobre ela, traduzindo-a literalmente; em que há um sujeito, aquele que pratica o ato de contemplação e abstração cognitivas e se pronuncia sobre ela, falando como seu representante autorizado, tendo diante de si o sujeito mudo, a coisa muda.

Nesta via, Bakhtin nos alerta que, por processos de naturalização, qualquer objeto de conhecimento (incluindo o homem) pode ser percebido e estudado e conhecido a título de coisa. E aí está a questão maior: o Sujeito, diz Bakhtin, não pode ser estudado, percebido a título de coisa, porque, como sujeito de lin-

\footnotetext{
9 Deleuze e Guattari (1997a) propõem para cada modo de pensamento um plano: para o modo de pensamento conceitualfilosófico propõem traçar um plano de consistência para os conceitos onde acolher suas variações; para o modo de pensamento científico, um plano de referência, onde definir suas variáveis; e para a arte, um plano de composição, onde experimentar suas variedades; planos de natureza diferente, cada um com componentes próprios, mas que podem se articular, se deixar hibridar uns pelos outros.
} 
guagem, não pode, em permanecendo sujeito, ficar mudo; e conseqüentemente o conhecimento que se tem dele só pode ser dialógico. Nesta via, dar voz ao sujeito da linguagem (o qual entendemos ao mesmo tempo como sujeito da educação e sujeito da pesquisa), significa trabalhar com as linguagens, com as possibilidades de expressão de sentidos nos encontros contextualizados, historicizados, em que os sentidos se produzem enquanto efeitos das misturas nos coletivos e no entrecruzamento com outros sentidos. Vale dizer, os sentidos se produzem enquanto efeitos de um contexto vivencial, regido por uma ética das relações e uma estética da existência. É desses sentidos que propomos fazer a escuta: uma escuta instituída numa relação de solidariedade com a intervenção, uma intervenção, ela própria constituída em escuta. Eis alguns efeitos dos recortes no plano de uma pragmática. Não que o discurso monológico ${ }^{10}$ (i.e. autoritário ou despótico) não se instaure, podendo ser banido, em benefício de uma pretensa pureza dialógica; pode-se, antes, considerar que monologia e dialogia coexistem no discurso sempre em uma relação de tensão, podendo, um ou outro, afirmar-se segundo determinadas condições de produção do discurso:

Em suma, temos então dois efeitos, conforme a ótica em que se examine a relação entre o si e o outro: (a) efeito de uma dialógica, de uma interação da ordem do intensivo, em que um si responsivo está sempre em busca de um outro, e de um outro responsivo que faça a escuta entre e através dos discursos, mesmo em situações de confronto; (b) efeito de uma monológica, da ordem do extensivo, em que, então, se instala o império despótico e/ou autoritário de um só discurso, em que a diversidade de linhas de criação e sentido é bloqueada em sua produção e a dimensão responsiva sofre apagamento. Esses efeitos, por outra parte, se desdobram em dois agenciamentos em tensão constante de confronto sistemático e irredutíveis entre si...(AXT, 2006:265).

Lembro aqui, também, a discussão de Deleuze e Guattari (1997a:28), a respeito do conceito de Outrem: um conceito complexo que, em sendo interrogado sobre se é segundo em relação a um eu, tem como uma possível resposta, que pode sê-lo, na medida em que seu conceito é aquele de um outro - sujeito que se apresenta como um objeto especial com relação ao eu: são dois componentes. Com efeito, se nós o identificarmos a um objeto especial, Outrem já não é outra coisa senão o outro sujeito, tal como ele aparece para mim; e se nós o identificarmos a um outro sujeito, sou eu que sou Outrem, tal como the apareço. [...] Mas tudo muda evidentemente se acreditamos descobrir outro problema: em que consiste a posição de Outrem, que outro sujeito vem somente 'ocupar' quando ele me aparece como objeto especial, e que eu venho, por minha vez, ocupar como objeto especial, quando eu the apareço? Deste ponto de vista, Outrem não é ninguém, nem sujeito nem objeto. Há vários sujeitos porque há Outrem, não o inverso. Outrem exige, então, um conceito 'a priori' de que devem derivar o objeto especial, o outro sujeito e o eu, não o contrário. A ordem mudou [...].

Numa perspectiva dialógica, que acolhe as interpretações do leitor, o texto dos autores referidos nos permite supor que dependendo da ótica segundo a qual se considere o conceito de "outrem", ele tanto pode ser interpretado como um problema concernente à pluralidade de sujeitos (outrem) - sua relação, sua apresentação recíproca; quanto pode ser entendido como uma posição exterior à relação, operando como o padrão normatizado e monológico da cultura (Outrem). Outras interpretações seriam possíveis, mas pelo menos duas constituindo um campo de forças em confronto estão dadas, colocando em relação dramática de tensão e de coexistência as perspectivas dialógica e monológica.

Por este viés, pode-se dizer que cada encontro entre sujeitos de linguagem adquire o caráter de acontecimento, por sua natureza de imprevisibilidade relacional e de sentidos: a expressão dos sentidos mediados pela linguagem, as produções de enunciados, de textos-linguagens, estão sempre na iminência de encontro com outros enunciados, com outros textos-linguagens, podendo engendrar, nos pontos de contato (que são constitutivos de contextos), outros enunciados, outros sentidos (sempre em devir, em acontecendo): Bakhtin (1997:404) refere ao "caráter de acontecimento da cognição dialógica, no encontro com o outro", parecendo que ressoa, por uma certa via, no pensamen-

\footnotetext{
${ }^{10}$ Nossa ancoragem conceitual com referência a uma relação monológica se dá simultaneamente em Deleuze e Guattari (1997c), quando tratam da palavra de ordem e dos regimes de sobrecodificação despótica e/ou autoritária; e em Bakhtin (1997), quando trata do discurso monológico, autoritário, que somente explica, e não interpreta, e que, ao não exercitar a escuta, produz o apagamento da polissemia e da polifonia constituintes da palavra.
} 
to de Deleuze (1998:9): o “acontecimento é coextensivo ao devir e o devir, por sua vez, é coextensivo à linguagem". O sentido, embora seja atribuído às coisas, só se exprime através da linguagem (ib.:157); daí o caráter acontecimental da linguagem, o sentido sendo o próprio acontecimento. O mesmo, supomos, dar-se-á em relação às demais linguagens em sua instância expressiva.

Nesta cena, o sujeito da pesquisa como sujeito de linguagem, enquanto coletivo hibridizado por fatos/conceitos/coisas ... tem e diz a sua palavra, intervindo, interferindo na pesquisa e nos seus resultados: ele deixa de ser objeto de pesquisa, para ser parceiro na experimentação, enquanto a experimentação, em si, passa a ser afetada também pela palavra dos parceiros, emergindo como um contexto dialógico de produção de sentidos, como uma pragmática. O que não quer dizer ${ }^{11}$, em absoluto, uma identificação entre pesquisador e parceiros da experimentação (ou sujeitos de pesquisa), muito menos uma identificação da proposta de pesquisa com uma experiência de vida (ou uma narrativa biográfica), uma vez que a cada movimento de implicação-vivenciação, corresponderá solidariamente um movimento de distanciação-explicação (ou ainda de tradução interpretativa, não literal).

Trabalhar com o pressuposto dialógico em pesquisa é, antes, considerar múltiplas vozes, em relação de tensão entre si, tanto as vozes dos participantes da experimentação, quanto as vozes dos autores de referência teórica e a do pesquisador-autor, no âmbito de uma relação de confronto mais ampla entre campos de força monológicos e dialógicos. E uma experimentação, que se pauta pelo princípio dialógico, trata participantes e autores de referência, como interlocutores e parceiros, no engendramento, tanto dos interrogantes da investigação, quanto dos enunciados interpretativos da experimentação.

Este ponto leva (quase inexoravelmente) a um terceiro e último ponto, o qual considera-se ser relevante para pensar a pesquisa em Educação no contemporâneo: estar implicado no contexto de produção da experimentação, considerar a relação dialógica do pesquisador com os contextos da pesquisa, nos quais ele próprio imerge (vale dizer, com os coletivos que aí habitam e dos quais ele próprio se torna parte integrante), retira do pesquisador a possibilidade autoritária de explicação monológica e de tradução literal: esta será substituída pela possibilidade de interpretacão, ou então de uma explicação, mas no sentido de uma tradução interpretativa, não literal.

Nesta via, não teremos tanto uma racionalização explicativa em forma de causas e efeitos, mas um aprofundamento dos sentidos no encontro com os sentidos do outro ou de outrem, também de Outrem, abrindo à interpretação compartilhada, sem dúvida tensionada pelas confrontações outrem-Outrem, mas favorecendo a ampliação das distâncias contextuais pela mútua e recíproca implicação de sujeitos num mesmo coletivo, em virtude do movimento de implicação-vivenciação; é num outro movimento, de distanciação-explicação, solidário com o primeiro, que se esperará do pesquisador um trabalho interpretativo, de tradução não-literal que remeta aos achados da pesquisa, cuja natureza será inelutavelmente polifônica (pela multiplicidade de vozes que a compõe) e polissêmica (pelo universo de sentidos que abrange), graças aos processos anteriores, vivenciados, de interpretação compartilhada.

Encontramos orientação similar em autores diferentes como Amorim (op.cit.) e Ricoeur (1983). É Miguel Baptista Pereira (prefaciador do livro Metáfora Viva de Paul Ricoeur) que chama a atenção para o pensamento do autor:

A pertença ou participação é uma experiência ou consciência do sentido vivido, que é interrompida pela distanciação ou epoche, a fim de ser explicitada e significada. Esta interrupção constitui a negatividade específica do signo linguístico ou do universo simbólico, que só pode significar se não for a realidade que significa. A epoche ou distanciação perante o vivido inaugura o "espaço vazio" em que os signos diferem uns dos outros e das coisas a que se referem e, enquanto emitidos, se distinguem dos signos recebidos. A fenomenologia explicita e tematiza esta epoche ou distanciação operatória imanente à experiência de pertença, fazendo aparecer o sentido enquanto sentido (RICOEUR, apud PEREIRA, 1983, p.x).

Entendemos, na esteira do autor, o espaço

\footnotetext{
${ }^{11}$ Numa alusão aos cuidados de ordem epistemológica para os quais nos chama atenção Amorim (2001, p. 17).
} 
vazio como o lugar em que se produz o sentido e o gesto de interpretação. Deleuze (1998) dirá que nos instalamos desde sempre, ou de saída, no sentido (na fronteira entre as coisas e a linguagem), não há um fora do sentido, este seria puro non-sense. É interessante trazer o pensamento do autor da citação, que vem da fenomenologia (Bakhtin e Deleuze também adotam, em momentos diversos, a perspectiva fenomenológica), por algumas convergências, como por exemplo: as noções de participação e pertença em uma experiência/experimentação, que diz da implicação radical dos sujeitos nos contextos de realidade; e as noções de distanciação e de espaço vazio, que lembram, tanto o conceito de exotopia em Bakhtin, quanto as noções de intervalo e descontinuidade propostas por Amorim com base em Bakhtin. $E$ todos estes enunciados lembram as noções de intervalo e de entretempos, de Bergson (1990), que seria onde Bergson situa a produção das intensidades da emoção criadora do sentido. Deleuze e Guattari (1997b;c) também tratam dos espaços lisos, não estriados, espécie de terra nova, que ainda precisa ser arada, estriada: podemos considerar espaços lisos ou vazios, as áreas virgens do pensamento vivencial e relacional, aquilo que ainda não pensamos, a serem habitadas pelo sentido mediante processos de invenção e de criação.

\section{De uma pragmática a uma analítica cartográfica}

Uma experimentação, no plano da pesquisa e formação, em nossa ótica, trata de constituir, como apoio às relações de convivência na linguagem, condições para a escrita: nas relações presenciais, tem o diário (de bordo, de campo, ou caderno de anotações ou de relatos.... $)^{12}$, explorado com o propósito con- creto de abrir e marcar espaços-tempo singulares para a voz do outro-participante da pesquisa-formação. Nas relações a distância, este papel de registro escrito da voz do outro cabe aos ambientes virtuais de comunicação coletiva, que então passam a operar como verdadeiros diários coletivos ${ }^{13}$. Neste caso particular da EAD, sujeitos de linguagem (também sujeitos da educação e da pesquisa) acoplados a ambientes virtuais (AV) podem constituir redes relacionais de convivência na linguagem, quando, então, os seus participantes passam a habitar estes ambientes pela escrita, através do exercício de suas vozes, erigindo-os em ambientes virtuais de aprendizagem (AVA) ${ }^{14}$. A voz se exercita pela escrita e a escrita dá corpo, materialidade à voz ${ }^{15}$ : vozes de todos os participantes, professor-aluno e pesquisador, vozes que, pela escrita, dão corpo a uma relação. Ao mesmo tempo, e justamente por isso, escrita enquanto corpo de uma relação se constitui num dispositivo que (por ser corpo) adensa e opacifica esta mesma relação, permitindo refratá-la e refleti-la para outro meio, outro plano, o do pensamento, o das tomadas de decisão e de posição.

Acredita-se, assim, que fazer uso, tanto de diários de campo enquanto suporte de escrita individual emprestando potência a pequenos grupos de estudo presenciais, quanto de redes de conversação na web enquanto suportes para a escrita coletiva, neste momento contemporâneo, cria um espaço privilegiado para a pesquisa com foco na formação, um locus para a problematização da ação, um locus para a interlocução dialógica, para a produção de sentido (AXT; MARTINS, 2008; SILVEIRA; AXT, 2008; AXT; ELIAS, 2003; AXT; KREUTZ, 2003).

Nos AVA, como ensaiado em Axt e Kreutz (ibid), o texto escrito coletivo, na conversação, se torna o suporte, por excelência, da interação e da relação. Mas, se de um lado

\footnotetext{
${ }^{12}$ Os pesquisadores do grupo têm optado por umas ou outras referências, segundo a literatura específica que têm consultado, e apropriando-se das mesmas em consonância com suas intenções particulares de pesquisa. Marcio A. R. Martins, José Ricardo Kreutz e Paloma Dias Silveira desenvolvem estudos de tese (os dois primeiros) e de dissertação (a terceira) muito ricos, sobre os diários de bordo nas redes presenciais, nos grupos de trabalho com professores do ensino fundamental. Paloma Dias da Silveira também desenvolve uma reflexão a partir de seu próprio diário enquanto estagiária em turma do Ensino Fundamental (www. lelic. ufrgs.br, publicações lelic).

${ }^{13}$ Gislei Lazzarotto vem desenvolvendo um estudo interessantíssimo em sua tese a respeito desta noção de diário coletivo. Ver também Mutti, R.; Axt, M. (2008).

14 Um estudo de tese, de Karla Rocha, vem focalizando este processo de transformação de um AV em um AVA, por mediação da escrita enquanto modo de relação entre os participantes do AV, enfatizando como o acoplamento produz mudanças ao mesmo tempo, nos participantes e no ambiente ou meio no qual a interação relacional acontece. (PPGIE/UFRGS).

${ }^{15}$ Um estudo de tese muito interessante, de Fernando Hartmann (PPGEDU/UFRGS) aprofunda esta questão.
} 
o texto será elemento inerente à organização deste espaço virtual, constituindo-o, de outro, por seu próprio operar, todo novo texto será, também, elemento estranho, imprevisível, que potencialmente irrompe na estrutura textual já dada, abrindo fissuras que podem levar a novas interpretações: neste sentido, cada novo texto sempre intervém de modo radical no plano individual-coletivo pesquisado da conversação, alimentando e rearranjando o próprio contexto conjuntural-estrutural. O texto pode, como efeito de uma intervenção, romper-se em sua teia de sentidos, implodindo a estrutura conceitual por regiões, regiões pontuais do texto conversacional, na medida em que cada intervenção carrega em si a multiplicidade polissêmica do sentido historicizado, e o "sentido nunca é solúvel no conceito" (BAKHTIN, 1997:402); isso, por sua vez, pode provocar desterritorializações, criando linhas de fuga (DELEUZE, 1998) - verdadeiras ramificações de natureza bifurcativa a mudar a trajetória da construção interlocutivo-interpretativa do coletivo, em andamento, no contexto da experimentação (em especial quando se tem um grande número de participantes). Essa instabilidade do conjunto textual-conceitual, instaurada por um agenciamento de enunciação calcado na escrita coletiva em processo interlocutivo, parece que gera uma demanda sem fim de novas contribuições: intervenções que pretendem dar conta do vazio, quando da implicação dos participantes (incluindo o pesquisador) no movimento para o dentro da dobra virtual, mas também do que faltou explicar no transbordamento para o fora do plano, assim constituindo um movimento, em rede, de enunciados ou textos-linguagens, conectados simultaneamente ao dentro e ao fora do plano da pesquisa, situado no contexto do AV. O efeito que vimos flagrando é o de engendramento de tomadas de posição que inelutavelmente transbordarão para fora do plano, criando outras possibilidades de ação/ interpretação, as quais trarão, por sua vez, para dentro do plano novos elementos para o trabalho interpretativo pela escrita, ampliando, multiplicando as linhas do dispositivo de enunciação coletiva.

Configura-se, por conseguinte, um longo texto, ao mesmo tempo coeso, coerente, e heterogêneo, repleto de incongruências, descontinuidades e linhas de fuga, vazios: in(ter) venções ou in(ter)ferências: inferências, em maior ou menor grau, do pensamento criador, com origem no esforço compreensivointerpretativo; pequenas invenções da subjetividade ${ }^{16}$ implicada para fazer sentido da(s) realidade(s) em que está imersa, transfiguradas em pequenas traduções não-literais, pequenas explicações parciais ou pequenos gestos de interpretação, num processo contínuo de produção de condições de possibilidade para outros (e novos) sentidos.

O dialógico, como dispositivo para a pesquisa-formação, produziu, para o nosso grupo de pesquisa, a base para uma metodologia de interação que, ao mesmo tempo, contempla os objetivos da pesquisa e da formação - a interação dialógica (AXT et al, 2006) .

A interação dialógica ampara-se nos autores que, ao longo do presente texto, têm se constituído em preciosos interlocutores para nós, em particular M. Bakhtin. Considera-se, assim, que toda relação dialogal, enquanto efeito de uma interação dialógica, implica necessariamente a alteridade (i.e. nas formas de outrem ou de Outrem) e que a toda expressão enunciativa (mesmo quando de efeito retardado em relação a uma expressão anterior) corresponde sempre uma atitude responsiva ativa prévia, dando conta de um contexto pragmático, interacional e enunciativo-responsivo, enquanto pressuposto de linguagem e de sujeitos de linguagem em relação.

Em nosso entendimento, será esta atitude ética de escuta inferencial, responsiva (desdobrando-se a um só tempo em suas duas faces, da respondibilidade e da responsabilidade) ${ }^{17}$, que se transfigurará, pela escrita, em disposi-

\footnotetext{
16 Tania Galli Fonseca (apud AXT et al., 2003, p. 262-263) nos fala de uma subjetividade como “[...] uma espécie de ambiente sociohistórico-afetivo, como uma ecologia das práticas, como um plano engendrado e significante a partir do qual produzir-se-ão múltiplas formas-sujeitos. Estas não se encontram dadas de vez e tampouco determinadas a priori [...] Ou seja, reservamos à agência humana uma capacidade de escolha orientada [...] o humano refere-se não a uma natureza; trata-se da nossa própria invenção."

17 “Em russo, a palavra otvetstnnost significa ao mesmo tempo respondibilidade e responsabilidade, conforme lembram Katerina Clark e Michael Holquist (1998), estudiosos do Círculo de Bakhtin. A tradução da obra A estética da criação verbal (BAKHTIN, 1997) contempla a palavra responsividade em seu texto, fundindo assim ambas as acepções" (AXT, 2006, p. 6). No mesmo texto, Axt defende que a arquitetônica da responsividade “[...] está profundamente implicada, tanto numa estética da criação do sentido na linguagem, quanto ainda numa ética do sentido para o outro, constituindo uma (est) ética dialógica e amorosa, fundada nos fluxos afectivos das relações interacionais".
} 
tivo disparador dos processos de opacificação e adensamento da relação interacional, num plano de pesquisa (e simultaneamente de formação). Tal permitirá que esta relação possa ser iluminada pela atenção, e ser refratada e refletida para o plano do pensamento e das tomadas de posição, transfigurando-se, mais uma vez, mas agora na ordem de uma estética (existencial-acadêmica).

A amplitude desse contexto dialogal (dialógico) é, para Bahktin (1997), sempre variável e pode incluir tanto um diálogo real entre dois interlocutores concretos (outrem), quanto um diálogo entre teorias, obras, épocas, culturas, paradigmas (a figura do Terceiro como ele denomina, ou de Outrem)... A escuta ativa, inferencial, compreensiva leva, mais cedo ou mais tarde, a réplicas multifacetadas, plurais e multíplices, que integrarão o fluxo dialógico, participando de sua composição. Em nosso entendimento, consideramos que possa estar implícito no conceito (bakhtiniano) de interação dialógica, o conceito de multiplicidade como formulado por Deleuze, que, neste contexto, adquire força de princípio:

Uma multiplicidade não tem nem sujeito nem objeto, mas somente determinações, grandezas, dimensões que não podem crescer sem que mude de natureza (as leis de combinação crescem então com a multiplicidade) [...] multiplicidade que muda necessariamente de natureza à medida que ela aumenta suas conexões [...] faz proliferar o conjunto [...] multiplicidade, não se deixa sobrecodificar [...] plano de dimensões crescentes segundo o número de conexões que se estabelecem nele. As multiplicidades se definem pelo fora: pela linha abstrata, linha de fuga ou de desterritorialização segundo a qual elas mudam de natureza ao se conectarem às outras [...] A velocidade transforma o ponto em linha ... linha de fuga (DELEUZE; GUATTARI, 2000:16-36).

Processos de escrita inferencial-interpretativa no conjunto de enunciações de um agenciamento, ao carregarem consigo o traço da multiplicidade (o que é da natureza dos sentidos historicizados compondo um conceito), produzem um efeito que emerge como um dissimilar, pondo à mostra, ao mesmo tempo, a natureza afirmativa das inferências e da intervenção, enquanto habitadas pela ação; e o caráter de excessividade (ou de excesso) da interpretação, enquanto habitada pelo sentido em sua mobilidade e multiplicidade. Por isso, instaurar um plano de pesquisa-formação não rompe com os contextos de realida- de concreta: toda interlocução engendrada no plano não deixa de confrontar continuamente os sentidos produzidos em sua historicidade - e novos sentidos assim produzidos no plano não deixam de carregar em si esta marca da história. Escutar/inferir/intervir/interpretar parecem ser dimensões de uma mesma operação que, no plano da pesquisa-formação, é simultaneamente de implicação e explicação (não-literal), e que se reconhece nos movimentos solidários de imersão-vivenciação no campo de realidade (recortado pela intenção subjetiva do pesquisador), e logo de emersãodistanciação desse campo.

Ora, de um certo ponto de vista do qual falávamos, entra-se com menos e sai-se com mais (vale dizer mais sentido, mais conceito, mais ação, mais teoria, mais filosofia, mais arte): tem-se, então, que afirmar, dissimilar/diferenciar e exceder são operações intrínsecas à esfera do sentido, que se fazem presentes também num plano particular ao pesquisar-formar. São efeitos, neste plano, dos movimentos de imersão-vivenciação e emersão-distanciação, são movimentos do viver-narrar, que transfiguram em sentidos as misturas de seres na fronteira com as linguagens. E, como tal, um plano de pesquisa-formação, traçado a partir das redes relacionais conversacionais, lembra/remete, na dimensão em que o estamos considerando, ao conceito de simulacro em Deleuze e Guattari (2000).

A idéia de simulacro sugere/traz na sua raiz o sentido de semelhante, similar (simile). Simular um estado de coisas é propor assemelhar em outro contexto o estado de coisas "original". Eis a armadilha da simulação, do simulacro: produzir, na superfície, uma imagem aparentemente idêntica ou semelhante, não quer dizer da sua efetiva semelhança, identidade. Espaço-tempo e outros componentes do contexto (superabundância informacional, educação como produto de consumo, currículo etc.) deixam de ser os mesmos, pela própria condição de produção de conversações, e se são modificadas as condições de produção de um estado de coisas, modifica-se também, por suposto, o contexto (um contexto é sempre único e irreversível de intervenção), e o próprio estado de coisas deixa de ser o mesmo: muda o sentido, repete-se o movimento que pretende replicar o sentido e produz-se a diferença. O simulacro não pode replicar a não ser a diferença; o que retorna, no simulacro 
(vale dizer, em nosso caso, no plano de uma escrita implicada em pesquisa-formação), não é o mesmo, não é o semelhante: aproveitando o que diz Deleuze (1988:468ss), a partir de Nietzsche, em sua discussão sobre o "eterno retorno", o que retorna é a afirmação, o dissimilar, o excessivo.

Em nosso entender são: a afirmação, o dissimilar, o excessivo (e podemos agregar aí também o multíplice), como elementos propulsores de responsividade, os que operam a opacificação, o adensamento da relação, colocando-a à mostra, na escrita, enquanto corpo, enquanto materialidade. $\mathrm{Na}$ medida mesma em que se produz o deslocamento de contexto e das condições de produção, produzem-se as condições para os deslizamentos de sentido que se dão na relação, e que por via da arquitetônica da responsividade, e do simulacro, afirmado como real, atual, se torna iluminado, visível, podendo ser refratado, refletido: o diálogo polifônico engendrado na multiplicidade das vozes (no dentro e no fora das fronteiras da experimentação), multiplica os contextos em articulação, os vazios, os intervalos produzindo o sentido polissêmico, as possibilidades de traduções não literais, vale dizer o alçamento a posições de enunciação, a posições enunciativas singulares, enquanto afirmação do diferente, do multíplice, caracterizando possibilidades de autoria na relação. Dizem da autoria neste contexto (incluída aí necessariamente a autoria coletiva, a co-autoria), as cartas engendradas no exercício cartográfico: cartas-diários (individuais-coletivos); cartas-relatórios/monografias de pesquisa, de formação; cartas-artigos científicos, ensaios, dissertações, teses; as cartas-imagens ${ }^{18} \ldots$

Num plano como o em que queremos operar em pesquisa-formação, a partir da experimentação, a própria analítica se dá também em processo, nos fluxos e movimentos que atravessam o próprio plano da experimentação, configurando um operar cartográfico, um movimento de 'leitura flutuante' em meio aos enunciados registrados, mapeando os pontos de intensidade bifurcativa e suas derivações. É o intervalo entre dois instantes que abre o espaço vazio, o entre-tempos, que precisa ser preenchido, conforme discute Bergson (1990); o entre-tempos é bifurcativo no sentido de que a suspensão do instante, num entre-tempos, obriga a uma escolha de sentido, fazendo aparecer o sentido enquanto sentido, para lembrar Ricoeur. Deleuze e Guattari nos ajudam a definir alguns termos de uma cartografia:

Cartografia [...] mapa e não decalque. [...]O mapa [...] contribui para a conexão dos campos, para o desbloqueio [...] O mapa é aberto, é conectável em todas as suas dimensões, desmontável, reversível, suscetível de receber modificações constantemente [...] Um mapa tem múltiplas entradas contrariamente ao decalque que volta sempre ao 'mesmo' (DELEUZE; GUATTARI, 2000:21-26).

Finalizo, sugerindo que a experimentação em pesquisa na educação (e no caso específico, da formação), na ótica em que vimos discutindo, remete a simulacro. Não interessa tanto a denominação, mas a função de dar corpo à relação, nas redes constituídas pela escrita: na relação virtual assim como na relação presencial, a escrita corporeifica a voz, dando-lhe materialidade e visibilidade pelas acoplagens que produz. E embora cada experimentação, levada à realização pelos integrantes do grupo de pesquisa, seja, antes de qualquer coisa, afirmação de diferença, algo retorna em cada uma delas, e cada uma das experimentações se encontra em todas as demais: como assegura Deleuze, a repetição, ela mesma "deriva necessariamente do jogo da diferença [...] a repetição no eterno retorno aparece como potência própria da diferença; e o deslocamento e o disfarce do que se repete só fazem reproduzir a divergência e o descentramento do diferente" (op.cit.:470).

De igual maneira, no interior de cada uma das variadas experimentações, a afirmação da relação dialógica e interacional, ao se repetir sem parar, repete a diferença, a diferença na repetição vestida como potência da diferença (ib.p.473). As distribuições relacionais por toda a rede de convivência, numa experimentação, são então nômades, móveis, imprevisíveis, dizendo recorrentemente do equívoco, do que faltou explicar ou traduzir não-literalmente, do sentido instaurado e deslocado de modo irreversível e para sempre, mas registrado nas

${ }^{18}$ É relevante considerar que a escrita, nestes contextos de pesquisa em educação possa ter um sentido ampliado para além da letra, alcançando a voz também através da imagem sonora e visual, trata-se de linguagens, como já enfatizado neste mesmo texto, linguagens de expressão, linguagens que dêem passagem aos sentidos. 
acoplagens com a escrita e, assim, por ela, enquanto corpo, podendo ser refratada, mesmo que de modo imperfeito, para o plano do pensamento, num exercício contínuo e só parcialmente bem sucedido de tradução não-literal: o exercício de cartografar (grafar em carta-relatório, escrever em letra, traçar em imagem visual ou sonora) o movimento, produzindo o mapa imperfeito; o exercício cartográfico da interpretação dos fluxos contextualizados do sentido postos em forma de escrita (de cartarelatório, de carta-letra, de carta-imagem...).
Esses achados nos levam a pensar que os processos de formação, assim como a pesquisa em educação que remete à formação, não têm fim, não há fórmulas a priori que dêem conta das mazelas, há apenas um sem fim de experimentações, intencionadas, a cada vez, a dar visibilidade e densidade à relação em sala de aula, na busca de sua refração contínua, como modo sistemático de abrir espaço para uma estética da expressividade e solidariamente a uma ética da escuta, como já dissemos em outro lugar ${ }^{19}$.

\section{Referências}

ALVES, E.; THOMAZ, A. R.; NUNES, C.; AXT, M. Objeto de aprendizagem CARTOLA: contando e recontando histórias na internet. In: NEVADO, R. A. de; CARVALHO, M. J. S. de; MENEZES, C. S. de M. (Orgs.). Aprendizagem em rede na educação a distância: estudos e recursos para formação de professores. Porto Alegre: Ricardo Lenz, 2007. p. 73-92.

AMORIM, M. O pesquisador e seu outro: Bakhtin nas ciências humanas. São Paulo: Musa, 2001.

AUGÉ, M. Não-lugares: introdução a uma antropologia da supermodernidade. São Paulo: Papirus, 1994.

AXT, M. Civitas, a cidade viva: ou de um espaço para o acontecimento-invenção na escola. Educação e Realidade, Porto Alegre, v. 29, n. 2, p. 219-235, 2004.

AXT, M. CIVITAS: abrindo espaços de invenção na escola. In: MOLL, J. (Org.). Múltiplos alfabetismos: diálogos com a escola pública na formação de professores. Porto Alegre: Ed. da UFRGS, 2005. v. 1, p. 17-39.

AXT, M. Comunidades virtuais de aprendizagem e interação dialógica: do corpo, do rosto e do olhar. Filosofia Unisinos, São Leopoldo, v. 7, n. 3, p. 256-268, set./dez. 2006.

AXT, M. CIVITAS: efeito rizoma entre a pesquisa e a extensão universitária. In: ARANTES, E. M. M.; NASCIMENTO, M. L. do. (Orgs.). Práticas PSI inventando a vida. Niterói: EDUFF, 2007. p. 91-102.

AXT, M.; ELIAS, C. R. Autoria coletiva, educação a distância e formação: de quando a aprendizagem reverbera o acontecimento. In: MARASCHIN, C.; LUCCA FREITAS, L. B.; CARVALHO, D. C. de. Psicologia e educação: multiversos sentidos, olhares e experiências. Porto Alegre: Ed. da UFRGS, 2003. p. 259-277.

AXT, M.; ELIAS, C. R.; COSTA, J. S.; SOL, E. L.; SILVEIRA, P. D. Interação dialógica: uma proposta teóricometodológica em ambientes virtuais de aprendizagem. RENOTE. Revista Novas Tecnologias na Educação, Porto Alegre, v. 4, p. 1, 2006.

AXT, M.; EM, E.; FONSECA, T. M. G.; LEITE, D. B. C.; MARASCHIN, C.; MUTTI, R. M. V.; SIVA, D. S. Tecnologias digitais na Educação: tendências. Educar em Revista, Curitiba, p. 237-264, 2003.

AXT, M.; KREUTZ, J. R. Instalando o tempo no espaço social da sala de aula em rede: ou de quando a autoria se (des) dobra em in(ter) venção. In: FONSECA, T. M. G.; KIRST, P. G. Cartografias e devires: a construção do presente. Porto Alegre: Ed. da UFRGS, 2003. p. 319-340.

${ }^{19}$ Ver Axt (2006). 
AXT, M.; MARTINS, M. Coexistir na diferença: de quando a formação em serviço pensa modos de habitar a sala de aula. In: TRINDADE, I. M. F. (Org.). Múltiplas alfabetizações e alfabetismos. Porto Alegre: Ed. da UFRGS, 2008. v. 1, p. 133-158.

BAKHTIN, M. A estética da criação verbal. São Paulo: Martins Fontes, 1997.

BERGSON, H. Matéria e memória: ensaio sobre a relação do corpo com o espírito. São Paulo: Martins Fontes, 1990.

DELEUZE, G. Diferença e repetição. Rio de Janeiro: Graal, 1988.

DELEUZE, G. O mistério de Ariana. Lisboa: Vega, 1996.

DELEUZE, G. A lógica do sentido. São Paulo: Perspectiva, 1998.

DELEUZE, G.; GUATTARI, F. O que é a filosofia? Rio de Janeiro: Ed. 34, 1997a.

DELEUZE, G.; GUATTARI, F. Mil Platôs: capitalismo e esquizofrenia. Rio de Janeiro: Ed. 34, 1997b. v. 5.

DELEUZE, G.; GUATTARI, F. Mil platôs: capitalismo e esquizofrenia. São Paulo: Ed. 34, 1997c. v. 2.

DELEUZE, G.; GUATTARI, F. Mil Platôs: capitalismo e esquizofrenia. V.1. Rio de Janeiro: Ed. 34, 2000. v. 1.

FIGUEIREDO, L. C. M. Matrizes do pensamento psicológico. Rio de Janeiro: Vozes, 1989.

HALL, S. A identidade cultural na Pós-Modernidade. Rio de Janeiro: DP\&A, 1998.

HERMANN, N. Metafísica da subjetividade na educação: as dificuldades do desvencilhamento. Educação \& Realidade, Porto Alegre, v. 4, n. 1, p. 81-94, 1997.

LATOUR, B. Jamais fomos modernos. Rio de Janeiro: Ed. 34, 1994.

MARASCHIN, C.; AXT, M. Acoplamento tecnológico e cognição. In: VIGNERON, J.; OLIVEIRA, V. B. (Orgs.). Sala de aula e tecnologias. São Bernardo do Campo: Ed. da UMESP, 2005. v. 1, p. 39-51.

MUTTI, R.; AXT, M. Para uma posição enunciativa no discurso pedagógico mediado por ambientes virtuais de aprendizagem. Interface. Comunicação, Saúde e Educação, Botucatu, v. 12, p. 1-21, 2008.

PEREIRA, M. B. Introdução à tradução portuguesa de Metáfora Viva de Paul Ricoeur. In: RICOUER, P. Metáfora viva. Porto: Rés, 1983.

PRIGOGINE, I.; STENGERS, I. A Nova Aliança: metamorfose da ciência. Brasília: Ed. da UnB, 1997.

SILVEIRA, P. D.; AXT, M. Diário de campo na formação docente: escrita, leitura e análise de experiências. In: VII SEMINÁRIO DA REDE DE ESTUDOS SOBRE TRABALHO DOCENTE: NOVAS REGULAÇÕES NA AMÉRICA LATINA, 2008, Buenos Aires. Anais..., Buenos Aires: Redestrado, 2008.

Recebido em março de 2008

Aceito para publicação em maio de 2008

\section{Margarete Axt}

Doutora em Lingüística e Letras pela Pontifícia Universidade Católica do Rio Grande do Sul (PUCRS).

Professora titular do Programa de Pós-Graduação em Informática na Educação (PPGIE) da Universidade Federal do Rio Grande do Sul (UFRGS).

maaxt@ufrgs.br 